\title{
GEOGRAPHIC VARIATION IN ASYMMETRIC COMPETITION: A CASE STUDY WITH TWO LARVAL ANURAN SPECIES
}

\author{
Iván Gómez-Mestre ${ }^{1}$ And Miguel TeJedo \\ Estación Biológica de Doñana, Consejo Superior de Investigaciones Científicas, Avda, M. Luisa s/n, E-41013, \\ Sevilla, Spain
}

\begin{abstract}
The outcome of interspecific competition may be modulated by a large number of factors, both biotic and abiotic. In this paper, we examined experimentally the effects of geographic variation, population density, and abiotic stress on the outcome of interspecific competition between two species of larval anurans. Three different populations of natterjack toad (Bufo calamita) were set to compete with common toad (Bufo bufo) in replicated artificial ponds under different combinations of osmotic stress (freshwater or brackish water) and intraspecific density (high and low). Among the B. calamita populations used, only one of them is sympatric to $B$. bufo and inhabits a freshwater environment. The two other populations, allopatric to $B$. bufo, occupy freshwater and brackish water environments, respectively. Survival, length of the larval period, and size at metamorphosis were analyzed at both the specific and the populational interaction levels. Intra- and interspecific competition did occur and generally resulted in a decrease in survival rates, an increase in the duration of the larval period, and a decrease in size at metamorphosis. Water salinity also prolonged the larval period and interacted with intra- and interspecific density, intensifying its effects. Interspecific competition was asymmetric, since $B$. bufo was competitively superior to $B$. calamita, causing larger effects on $B$. calamita than those experienced by $B$. bufo. However, the three populations of $B$. calamita showed different competitive effects and responses when they were set to compete with $B$. bufo. The population sympatric to $B$. bufo had the stronger competitive effect and response, causing a strong impact on survival, growth, and developmental rate of $B$. bufo. The allopatric population inhabiting the brackish environment also had a marked effect on $B$. bufo survival, although only at high density. The other allopatric population only had a significant effect on the size at metamorphosis of $B$. bufo. The impact of $B$. bufo on B. calamita was greater for the allopatric populations than for the sympatric one. This pattern suggests that the nature and outcome of ecological interactions are a function of environmental conditions and population history.
\end{abstract}

Key words: abiotic factors; amphibians; Bufo; geographic mosaic model; geographic variation; interspecific competition; intraspecific competition; local adaptation.

\section{INTRODUCTION}

Populations of species with a wide geographic distribution are likely to be exposed to a vast array of ecological conditions imposed by varying abiotic conditions and biotic interactions. The geographic mosaic theory states that this heterogeneity conforms to a mosaic of local selection pressures of varying intensities (hot spots and cold spots) that, together with gene flow, shape the spatial distribution of traits for that species (Thompson 1994, 1999, Gomulkiewicz et al. 2000). One of the ways of investigating the geographic mosaic theory is testing whether coevolved traits of an interaction differ among communities (Thompson 1999). However, the identity of the species that integrate a given community, and how close they are to their respective optimal conditions, is constrained by the set of abiotic factors acting upon the system, according to

Manuscript received 8 March 2001; revised 27 September 2001; accepted 19 December 2001

${ }^{1}$ E-mail: igmestre@ebd.csic.es the species' particular niches and tolerance limits (Hoffmann and Parsons 1991, Warner et al. 1991).

Competition is considered to be one of the most important determinants of the structure and dynamics of biological communities (Connell 1983, Schoener 1983, Underwood 1986). The outcome of competitive interactions is often modulated to a great extent by factors such as the abiotic conditions (Dunson and Travis 1991, 1994, Rowe and Dunson 1995, Newman 1998) or the relative intensity of predation (Morin $1983 a, b$ ). Amphibian larval guilds have been a fertile ground for the study of community structuring, interspecific interactions, and effects of environmental conditions on the outcome of interactions (Morin 1983a, Dunson and Travis 1991) because of their sensitiveness to environmental variation (both biotic and abiotic), and their relative easiness to handle experimentally. The combination of high population densities and relatively low niche differentiation makes it likely that interspecific competition takes place in tadpole assemblages (Alford 1999). Interspecific competition may be the main agent 
determining community structure in ponds of intermediate permanence, while in extremely ephemeral and permanent ponds the relative effect of abiotic factors (essentially pond duration) and predation, respectively, may prevail over competition (Faragher and Jaeger 1998). Both intra- and interspecific competition in amphibians are typically density dependent (Wilbur and Collins 1973, Travis 1980, Warner et al. 1993, Tejedo and Reques 1994, Newman 1998). In that sense, the study of interspecific competition not only is improved by the simultaneous study of intraspecific density effects, but it seems unreasonable to decouple the former from the latter, since the similarity of requirements for basic resources among conspecific individuals must be greater or at least as great as between species (Underwood 1986, Parsons 1996).

Several abiotic factors affect the outcome of intraor interspecific competition among anuran larvae, including water pH (Warner et al. 1991, 1993, Pehek 1995), pond duration (Tejedo and Reques 1994, Reques and Tejedo 1997), and temperature (Newman 1998). Another stress factor for amphibian tadpoles is water salinity (Balinsky 1981, Shoemaker et al. 1992), but to date this stressor has not been explored as potential modulator of competitive interactions among amphibian species. Inland brackish water environments are relatively frequent in the Mediterranean area and several amphibian species breed in them in spite of the osmotic stress induced. One such species is Bufo calamita, long considered a euryhaline toad (Balinsky 1981). Osmotic stress has been experimentally demonstrated to induce high mortality and a strong decrease in developmental rates in B. calamita embryos and larvae (Beebee 1985), directly and indirectly reducing fitness through reducing survival and opportunities to reach metamorphosis before pond desiccation (I. Gómez-Mestre and M. Tejedo, unpublished data). Also populational variation in tolerance to osmotic pressure has been observed in B. calamita (I. Gómez-Mestre and M. Tejedo, unpublished data). In turn, another bufonid species that largely overlaps in its distribution, Bufo bufo, is not found breeding in these kind of environments and thus we predict that the strength of biotic interactions between these two species may be affected by changes in osmotic conditions.

Evidence for geographic variation and local adaptation of life history traits in amphibians, reflecting a geographic mosaic of selection pressures, is accumulating (Berven 1982a, b. Figiel and Semlitsch 1990, Harris et al. 1990, Bernardo 1994, Kurzava and Morin 1994, Fauth 1998, Storfer and Sih 1998, Merilä et al. 2000). If substantial population differentiation occurs, the geographic-mosaic theory of coevolution predicts some degree of geographic variation in the intensity and outcome of interspecific interactions as well. To our knowledge, this aspect has been much less studied in amphibians and information is still scarce (Fauth 1998).
In this paper we examined the outcome of competitive interactions among Bufo bufo and three different populations of Bufo calamita during the larval phase using an array of artificial mesocosms. Both species range across Western Europe and B. bufo has been found to be competitively superior in some British populations (Denton and Beebee 1994, Bardsley and Beebee 1998a). In southern Spain the two species are widespread and sympatric in many places. Reproduction is almost synchronic although $B$. bufo is an earlier breeder, preceding its congeneric by around one month. Both species breed in temporary habitats that differ in durability, those used by $B$. bufo being longer lasting than the ephemeral ponds used by $B$. calamita. However, rainfall is highly variable and affects the availability of breeding ponds so that larvae from both species often co-occur in the same ponds. Thus, there is potential for interspecific interactions during the larval phase. The three populations of $B$. calamita used in the experiments differed in their recent natural history with regard to the factors being analyzed, i.e., water salinity and syntopy with $B$. bufo.

The main hypotheses were (1) that the two bufonid species differed in their competitive ability and osmotic stress tolerance; and (2) different natterjack populations would respond differently in competitive interactions with common toads and in their tolerance to brackish water environments, thus reflecting microgeographic variations in the local selective factors. These hypotheses generated the following predictions: (1) There would be competitive dominance of B. bufo on $B$. calamita, but it would be less under brackish water and high-density conditions because $B$. bufo does not occur either in brackish environments (probably as a consequence of a poor tolerance to osmotic stress) or in crowded, ephemeral ponds, like $B$. calamita does; (2) The B. calamita population syntopic to $B$. bufo would exhibit a higher competitive response (sensu Goldberg and Landa 1991) to interspecific competition than would allotopic populations; and (3) The B. calamita population coming from a brackish environment would show a higher osmotic tolerance than those coming from freshwater ones.

\section{Methods}

\section{Source populations}

Three populations of $B$. calamita located in the province of Córdoba, southern Spain, were chosen for the experiment because of their different historical relationship with the factors under study. The first population, Fresh 1, breeds in the same freshwater stream as the chosen $B$. bufo population. The other two populations do not naturally coexist with $B$. bufo. At least during $15 \mathrm{yr}$ of surveys no $B$. bufo were observed breeding in these ponds or in the near surroundings. These two allotopic populations, Fresh 2 and Saline, breed in freshwater and brackish water ponds, respec- 
tively. All these populations are separated by distances beyond the dispersal ability of adults. Fresh 2 is $\sim 80$ $\mathrm{km}$ away from both Saline and Fresh 1 while the two latter are separated by $30 \mathrm{~km}$. However, there are other temporary breeding ponds in between that could allow gene flow among these populations.

The three aquatic systems are temporary. The Saline population breeds in a brackish lagoon, the Laguna de los Jarales reserve, of $\sim 2.6$ ha with a maximum depth of $1.2 \mathrm{~m}$. This lagoon is moderately mineralized, showing a salinity range over the last $15 \mathrm{yr}$ of between 2.3 and $18 \mathrm{~g} / \mathrm{L}$. The Fresh 1 population breeds in a stream running across a grassland plain at $950 \mathrm{~m}$ above sea level. The Fresh 2 population breeds in a mosaic of small and shallow ponds in Sierra Morena (see description in Tejedo 1992).

The experiment was conducted in the Reserva Integral de la Laguna Amarga, located near the populations of Saline and Fresh 1. Six recently laid clutches of B. bufo eggs were collected between 11 and 17 January 1998. During the night of 2 February, after a period of heavy rain, we collected six clutches of $B$. calamita from Fresh 2 and another six from Saline that were also brought to the laboratory. On 9 February we collected six samples from a number of $B$. calamita clutches in Fresh 1 that were in a similar developmental stage to those from Fresh 2 and Saline. A total of 500 larvae from each of three $B$. calamita populations and another 800 larvae from the $B$. bufo population were removed and reared in plastic trays until they reached developmental stage 25 (Gosner 1960). All B. calamita larvae from all three populations were synchronized, while $B$. bufo larvae were 15-20 d older than B. calamita by the time the experiment started.

\section{Experimental design}

We measured the effects of population density and osmotic stress on survival, size, and time to metamorphosis on assemblages of B. calamita and B. bufo. The design consisted of a three-factor fractional factorial design with water salinity, intraspecific density, and presence of heterospecifics as main factors. Densities of 15 and 30 tadpoles per enclosure simulated the low and high intraspecific densities for $B$. bufo and each of the B. calamita populations. Presence or absence of competitors was modulated following an additive design rather than following a substitutive one (Underwood 1986), implying that heterospecifics were added while density of the former species remained equal to the density set for the absence of competitors (15+ 15 or $30+30$ tadpoles per enclosure, respectively, depending on the density level). Finally, two levels of water salinity, fresh and brackish, were established. Both types of water were taken from natural breeding ponds and had a total salinity of $<0.4$ and $5 \mathrm{~g} / \mathrm{L}$, respectively. The design implied 28 treatments that were arranged in a randomized block design with four rep-
TABLE 1. Experimental matrix of all possible interactions among density, competition, and salinity stress.

\begin{tabular}{|c|c|c|c|}
\hline \multirow{2}{*}{$\begin{array}{c}\text { Bufo } \\
\text { calamita } \\
\text { origin and } \\
\text { density } \\
\text { (individuals/ } \\
\text { enclosure) } \\
\end{array}$} & \multicolumn{3}{|c|}{ Bufo bufo density (individuals/enclosure) } \\
\hline & 0 & 15 & 30 \\
\hline \multicolumn{4}{|l|}{ A) Freshwater } \\
\hline $\begin{array}{c}\text { Saline } \\
0 \\
15 \\
30\end{array}$ & $\begin{array}{c}\cdots \\
1 \\
2\end{array}$ & $\begin{array}{r}7 \\
9 \\
\ldots\end{array}$ & $\begin{array}{c}8 \\
\ldots \\
10\end{array}$ \\
\hline $\begin{array}{c}\text { Fresh } 2 \\
0 \\
15 \\
30\end{array}$ & $\begin{array}{r}\cdots \\
3 \\
4\end{array}$ & $\begin{array}{r}7 \\
11 \\
\ldots\end{array}$ & $\begin{array}{c}8 \\
\ldots \\
12\end{array}$ \\
\hline $\begin{array}{c}\text { Fresh } 1 \\
0 \\
15 \\
30\end{array}$ & $\begin{array}{r}\cdots \\
5 \\
6\end{array}$ & $\begin{array}{r}7 \\
13 \\
\cdots\end{array}$ & $\begin{array}{r}8 \\
\ldots \\
14\end{array}$ \\
\hline $\begin{array}{l}\text { B) Brackish u } \\
\text { Saline }\end{array}$ & ater & & \\
\hline $\begin{array}{r}0 \\
15 \\
30\end{array}$ & $\begin{array}{l}\ldots \\
15 \\
16\end{array}$ & $\begin{array}{l}21 \\
23 \\
\cdots\end{array}$ & $\begin{array}{l}22 \\
\ldots \\
24\end{array}$ \\
\hline $\begin{array}{c}\text { Fresh } 2 \\
0 \\
15 \\
30\end{array}$ & $\begin{array}{l}\ldots \\
17 \\
18\end{array}$ & $\begin{array}{l}21 \\
25 \\
\ldots\end{array}$ & $\begin{array}{l}22 \\
\ldots \\
26\end{array}$ \\
\hline $\begin{array}{c}\text { Fresh } 1 \\
0 \\
15 \\
30\end{array}$ & $\begin{array}{l}\ldots \\
19 \\
20\end{array}$ & $\begin{array}{l}21 \\
27 \\
\ldots\end{array}$ & $\begin{array}{l}22 \\
\ldots \\
28\end{array}$ \\
\hline
\end{tabular}

Notes: The density columns and rows refer to the intraspecific density (number of tadpoles) set at each treatment. The numbers in the matrix designate the cells (treatments) to be used in the contrast analysis in order to test specific effects. Cells with the same value represent the same experimental treatment. For instance, the cell numbered 8 represents the replicates belonging to the treatment in which $B$. bufo is set at high intraspecific density but with no interspecific tadpoles in freshwater. A contrast for the intraspecific density effect in $B$. calamita contrasted cells $1,3,5$ and $15,17,19$ against $2,4,6$ and $16,18,20$.

licates and a total of 112 experimental units. Table 1 shows all combinations in the design.

Experimental units consisted of square plastic boxes $0.50 \times 0.37 \times 0.28 \mathrm{~m}$ as artificial ponds located outdoors and were filled with $40 \mathrm{~L}$ of water a week before the beginning of the experiment. Temperature, water levels, and salinity were periodically checked and salinity (measured with an electronic conductivity meter Omega CDH-46, Omega, Stamford, Connecticut, USA) was adjusted within and among blocks. No strict salinity was fixed. We allowed it to increase as water evaporated from the boxes and restrained it so that it would not surpass $10-11 \mathrm{~g} / \mathrm{L}$, adding a similar amount of freshwater to all boxes. The boxes remained uncovered, and care was taken to eliminate any potential predators that accidentally entered the boxes. Tadpoles were fed $0.15 \mathrm{~g}$ of rabbit chow twice a week regardless 
of tadpole density. Three censuses were made during the experiment and prior to metamorphosis. Two boxes had to be discarded for analyses due to the attack of a viperine snake (Natrix maura) that preyed upon the tadpoles.

Metamorphic toads first began to emerge on 2 April for B. bufo, and on April 4th for B. calamita. Tadpoles were considered to be in metamorphosis when at least one forelimb protruded, i.e., when they reached Gosner stage 42 (Morin 1983a, Tejedo and Reques 1994). After the occurrence of the first metamorph, the boxes were checked daily and metamorphs removed and kept in the laboratory in individual Petri dishes $(9 \mathrm{~cm}$ diameter) filled with humidified moss until they completed tail resorption. Towel-dried wet mass of toadlets was then measured to the nearest $0.1 \mathrm{mg}$ using a precision balance Mettler Toledo AG245 (Mettler Toledo, Geifensee, Switzerland), after which all toadlets were returned to their original population site.

\section{Statistical analyses}

We analyzed the data using a cell-means approach to a general linear model (Searle 1987) and a contrast analysis through planned comparisons (Dunson and Travis 1991) to test for the existence of interspecific competition. Since our analysis involved not only the mutual competitive effects under varying abiotic conditions, but also the effect of both biotic and abiotic factors on conspecific populations with different natural histories determined by a different ecological background, we further modified the model proposed by Dunson and Travis (1991). First, a one-way ANOVA was carried out on each species and response variable in which all the cells with various treatment combinations where a particular species is present in the design were used as class factors. Where overall ANOVA results were significant, a contrast analysis was carried out to test for a specific biological hypothesis. For our three $B$. calamita populations, seven contrasts are sufficient to test for main effect of salinity, intraspecific, and interspecific effects, and for all possible interactions among the main effects. An additional eighth contrast can be performed to test for the equivalence of intraspecific and interspecific density on the response variables, e.g., that $B$. calamita may be equally affected by the addition of 15 conspecifics or by the addition of $15 \mathrm{~B}$. bufo. This test per se is not a contrast for the effects of interspecific competition because it already assumes that competitive effects are occurring (Dunson and Travis 1991), and it should not be done if neither of the previous contrasts for the effect of interspecific competition is significant. With respect to $B$. bufo, the calculations are further complicated because it is independently confronted with three different $B$. calamita populations, in which case there are 14 possible contrasts. An inherent difficulty of this design is the lack of orthogonality among some of the contrasts required, as well as the need for comparison-wise error rate ad- justment due to the large amount of contrasts performed. Thus we minimized the number of comparisons by discarding those response variables for which the initial one-way ANOVA was nonsignificant, and by avoiding the calculation of equivalence contrasts when any of the interspecific contrasts was nonsignificant. We adjusted the significance level of the tests following the Dunn-Sidak algorithm (Sokal and Rohlf 1995). We used the mean of individual responses for each box as the effect of any given treatment on a particular experimental unit to avoid pseudoreplication of individual measures within boxes (Hurlbert 1984, Tejedo and Reques 1994).

Survival rates were angularly transformed by the arcsine-square-root transformation, and mass at and time to metamorphosis were ln-transformed in order to reduce skewness (Snedocor and Cochran 1989). Survival was introduced as a covariate in the analysis of both length of the larval period and mass at metamorphosis. The initial overall ANOVA yielded a significant block effect on both mass at and time to metamorphosis, and thus further analyses were corrected for block effect. All calculations were made with the PROC GLM from SAS statistical package (SAS Institute 1990).

\section{RESUlts}

Species level responses

\section{Bufo calamita.-}

1. Water salinity.-Being raised in either brackish or freshwater did not significantly affect survival rates of $B$. calamita. Salinity had a marginally significant effect on the duration of the larval period $\left(F_{1,90}=7.65\right.$, $\left.P=0.0069, \alpha^{\prime}=0.0064\right)$, which was prolonged by $7.6 \mathrm{~d}$ under brackish conditions (Fig. 1). The mean mass of $B$. calamita at metamorphosis experienced an increase of $\sim 28 \%\left(F_{1,90}=13.87, P<0.001\right)$ in saline water treatments with respect to freshwater. A correlation between mean date of and mean mass at metamorphosis for B. calamita yielded coefficients of $r=$ 0.67 at low density, and $r=0.03$ at high density, both in the absence of heterospecifics.

The interaction effect between intraspecific density and water salinity increased the duration of the larval period, and again was marginally significant $\left(F_{1,43}=\right.$ $6.41, P=0.015)$. Both main factors exerted a similar effect in intensity and direction on date of metamorphosis at the higher stress levels (brackish water or crowding), extending the length of the larval period.

A similar effect was observed with the interaction of water salinity and the presence of B. bufo. B. calamita delayed metamorphosis $10.4 \mathrm{~d}$ when $B$. bufo was added, independently of water salinity.

2. Intraspecific density.-Intraspecific density did not contribute significantly to reduce survival of $B$. calamita larvae. In turn, the length of the larval period was increased and the mean mass at metamorphosis was reduced at high intraspecific densities (see Table 

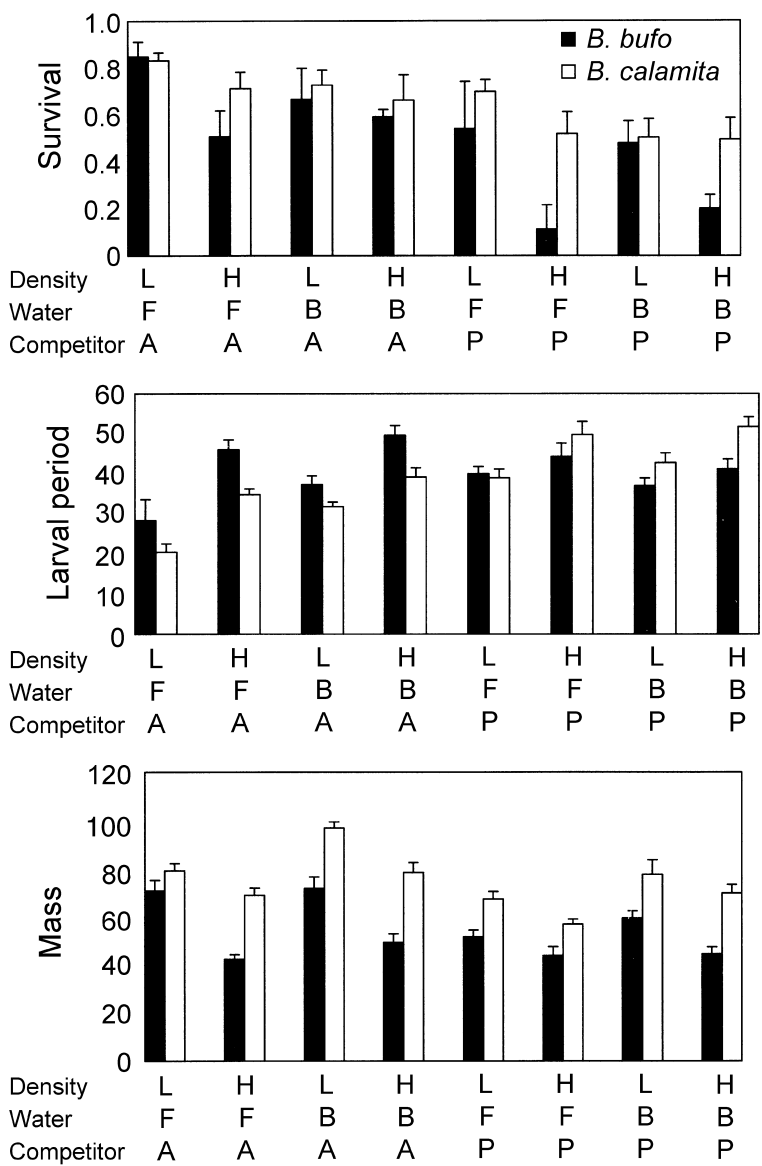

FIG. 1. Means of the response variables at the species level across all experimental treatments. $\mathrm{L}$ and $\mathrm{H}$ stand for low and high density treatments; $\mathrm{F}$ and $\mathrm{B}$ for fresh and brackish water treatments; and $\mathrm{A}$ and $\mathrm{P}$ for absence and presence of heterospecific tadpoles. Larval period is measured since the beginning of the experiment. Mass was measured at tail reabsorption (Gosner stage 46). Error bars indicate +1 SE.

$2)$. The mean delay in the mean date at metamorphosis was of $12.1 \mathrm{~d}(F=17.09, P<0.001)$. Mean mass at metamorphosis was lowered from 87 to $72 \mathrm{mg}$, a $16.8 \%$ loss of body mass $\left(F_{1,45}=14.9, P<0.001\right)$.

3. Interspecific density.-The presence of B. bufo significantly lowered the survival probability of $B$. calamita $\left(F_{1,91}=11.94, P<0.001\right.$; Fig. 1$)$. Nevertheless, when the effect was tested separately for the two density levels, results were not significant at the adjusted significance level. The interaction between intraspecific density and presence of $B$. bufo was not significant, implying that the effect of the combined stresses was additive. Duration of the larval period was increased by 15 and $13 \mathrm{~d}$, respectively, at low and high density $\left(F_{1,45}=25.67, P<0.001 ; F_{1,43}=30.21, P<\right.$ 0.001 , respectively) in the presence of $B$. bufo. Mass at metamorphosis decreased $18 \%$ at low and $13 \%$ at high density, though the latter test was not significant $\left(F_{1,45}=14.13, P<0.001 ; F_{1,43}=7.13, P=0.01\right.$, respectively). As in the case of the two previous variables discussed, there was no significant interaction between intraspecific and interspecific densities, suggesting that the effect of these two sources of stress is additive.

Bufo bufo.-

1. Water salinity.-Water salinity did not significantly affect the survival and development of B. bufo. Even though the contrast analysis failed to show a direct significant effect of this factor on any of the three response variables, it behaved additively in relation to the other two sources of stress, contributing to reduce the survival rate of $B$. bufo at either intraspecific density.

2. Larval density.-High intraspecific density only significantly decreased survival when the heterospecific competitor was present $\left(F_{1,46}=14.0, P<0.001\right)$. Interspecific competition only affected survival of $B$. bufo significantly at high density, reducing it from 0.55 to $0.25\left(F_{1,46}=8.81, P<0.005\right)$. At low density only a slight tendency towards mortality increase could be detected. Duration of the larval period was considerably increased when intraspecific density was raised $\left(F_{1,37}=23.17, P<0.001\right.$; see Table 2$)$, metamorphosing a week later than their controls at low density. Date of metamorphosis remained unaffected by the addition of B. calamita at either density. Mass at metamorphosis was clearly diminished when intraspecific density was raised $\left(F_{1,34}=21.1, P<0.001\right)$, falling

TABLE 2. Summary of effects of the main experimental factors on the response variables at the species level.

\begin{tabular}{|c|c|c|c|c|c|c|}
\hline \multirow[b]{2}{*}{ Response variable } & \multicolumn{3}{|c|}{ B. calamita } & \multicolumn{3}{|c|}{ B. bufo } \\
\hline & Salinity & $\begin{array}{l}\text { Intraspe- } \\
\text { cific } \\
\text { density }\end{array}$ & $\begin{array}{c}\text { Presence of } \\
\text { hetero- } \\
\text { specific }\end{array}$ & Salinity & $\begin{array}{c}\text { Intraspe- } \\
\text { cific } \\
\text { density }\end{array}$ & $\begin{array}{c}\text { Presence of } \\
\text { hetero- } \\
\text { specific }\end{array}$ \\
\hline Survival & $\ldots$ & $\ldots$ & -24.5 & $\ldots$ & $\ldots$ & $\ldots$ \\
\hline Larval period & 55.9 & 69.8 & 90.7 & $\ldots$ & 62 & 40.8 \\
\hline Mass at metamorphosis & 22.8 & -12.7 & -15.2 & $\cdots$ & -40.9 & -26.8 \\
\hline
\end{tabular}

Notes: Only significant effects are shown. Values shown are percentages by which the response variable was affected as contrasted with the experimental controls in freshwater, low density, and absence of competitors. Positive values represent increases, while negative values show decreases. 


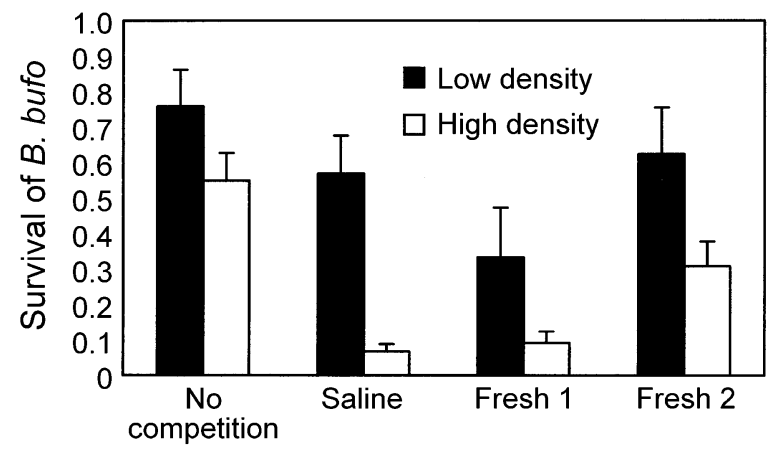

FIG. 2. B. bufo survival in the absence of B. calamita, and in competition with each of the three B. calamita populations. Error bars indicate +1 SE. Fresh 1 and Saline have the strongest impact, while the competitive effects of Fresh 2 are negligible. Fresh 1 reduced survival of B. bufo $47 \%$ at low population density and $82 \%$ at high density. The effect of Saline was only significant at high density where it represented a $92 \%$ decrease in survival of $B$. bufo.

from a mean 71.2 to $45.9 \mathrm{mg}$. Interspecific competition was only relevant in reducing the mass at metamorphosis when it occurred under low density conditions $\left(F_{1,34}=17.12, P<0.001\right)$. Since mean mass at metamorphosis was sensitive to both intra- and interspecific density, we conducted a contrast for equivalence of competitors, which was found to be significant $\left(F_{1,34}\right.$ $=9.44, P<0.005)$. Conspecifics caused a more severe reduction of body mass of $B$. bufo than heterospecific competitors (35.4 and 19.9\%, respectively; Fig. 1).

\section{Population level responses}

Differential effect on B. bufo.-The three B. calamita populations affected differently the performance of $B$. bufo. Survival of $B$. bufo was significantly affected by Fresh 1 at low and high density $\left(F_{1,44}=10.60\right.$, $P<0.003 ; F_{1,44}=9.63, P=0.003$, respectively $)$, by Saline at high density $\left(F_{1,44}=9.83, P=0.003\right)$, and was unaffected by Fresh 2 in all cases (see Fig. 2). The duration of the larval period of $B$. bufo remained unaffected in all three cases, while mass at metamorphosis was significantly reduced by Saline at low density $\left(F_{1,44}\right.$
$=15.74, P<0.001)$. This effect was marginally significant in the case of Fresh 1 and Fresh $2\left(F_{1,44}=8.45\right.$, $P=0.006$ and $F_{1,44}=8.86, P=0.005$, respectively).

Saline.-Neither the increase in intraspecific density, the addition of an interspecific competitor, or the switch from freshwater to saline water seemed to affect the survival or the mass at metamorphosis of B. calamita larvae from the brackish pond of Saline (see Table 3). In turn, the larval period length was considerably dependent on the two biotic interactions. Increased intraspecific density significantly delayed duration of the larval period $\left(F_{1,17}=10.72, P<0.005\right)$, as did competition with $B$. bufo (mean 17.2 and $19.6 \mathrm{~d}$, respectively), though the effect was only significant at low density $\left(F_{1,17}=17.26, P<0.001\right)$. The contrast of equivalence between competitors, opposing those treatments with 30 Saline larvae in it against those with 15 Saline larvae plus 15 B. bufo larvae was not significant.

Fresh 1.-The survival and mass at metamorphosis of the individuals belonging to the population of Fresh 1 was not affected by any of the factors considered (see Table 3). In turn, increasing the intraspecific density clearly elongated the larval period $\left(F_{1,20}=16.46, P<\right.$ $0.001)$, postponing the date of metamorphosis a mean of $9.3 \mathrm{~d}$. The addition of heterospecific competitors delayed the date at metamorphosis but the effect was only significant at low density $\left(F_{1,20}=19.6, P<0.001\right)$. The mean date of metamorphosis was delayed a maximum of $20 \mathrm{~d}$ when combined with a high density of conspecifics. The contrast of equivalence between competitors was conducted and found not to be significant. As in the previous case, the saline environment fails to show a statistically significant effect on the duration of the larval period.

Fresh 2.-As in the case of the other two B. calamita populations, survival of the larvae from Fresh 2 was not significantly affected by any of the experimental treatments, and no contrast analysis was thus conducted on this variable. On the other hand, all three main factors significantly conditioned the duration of the larval period and all of them caused delays of varying length in the timing of metamorphosis. Salinity of the water

TABLE 3. Population-level summary of main effects on the three B. calamita populations.

\begin{tabular}{|c|c|c|c|c|}
\hline \multirow[b]{2}{*}{ Factor } & \multirow[b]{2}{*}{ Response variable } & \multicolumn{3}{|c|}{ Populations } \\
\hline & & Saline & Fresh 1 & Fresh 2 \\
\hline Salinity & $\begin{array}{l}\text { survival } \\
\text { larval period } \\
\text { mass at metamorphosis }\end{array}$ & $\begin{array}{l}\cdots \\
\cdots \\
\cdots\end{array}$ & $\begin{array}{l}\cdots \\
\cdots \\
\cdots\end{array}$ & $\begin{aligned} & \cdots \\
+ & 100.6 \\
+ & 24.7\end{aligned}$ \\
\hline Density & $\begin{array}{l}\text { survival } \\
\text { larval period } \\
\text { mass at metamorphosis }\end{array}$ & $\begin{array}{c}\cdots \\
+74.9 \\
\ldots\end{array}$ & $\begin{array}{c}\cdots \\
+41.5 \\
\ldots\end{array}$ & $\begin{array}{l} \\
\cdots \\
+112.1 \\
-16.1\end{array}$ \\
\hline Presence of $B$. bufo & $\begin{array}{l}\text { survival } \\
\text { larval period } \\
\text { mass at metamorphosis }\end{array}$ & $\begin{array}{c}\cdots \\
+106(\mathrm{~L}) \\
\ldots\end{array}$ & $\begin{array}{l}\ldots \\
+49.8(\mathrm{~L}) \\
\quad \ldots\end{array}$ & $\begin{aligned} & \ldots \\
+ & 139.4(\mathrm{~L}),+63.7(\mathrm{H}) \\
- & 10(\mathrm{~L}),-20.6(\mathrm{H})\end{aligned}$ \\
\hline
\end{tabular}

Notes: Only significant effects are shown, and in the case of interspecific interaction, the intraspecific density level (L, low; H, high) at which the effect is significant is specified. The values indicate the changes in the mean of the response variable, expressed as a percentage of the experimental control mean under the different experimental treatments. 
was responsible for a mean delay of $10.3 \mathrm{~d}\left(F_{1,19}=\right.$ 10.33, $P<0.005)$. Differences in the experimental intraspecific densities accounted for a mean delay of $12.1 \mathrm{~d}\left(F_{1,19}=20.79, P<0.001\right)$. There was also a net interaction effect between the salinity of the water and the intraspecific density $\left(F_{1,19}=8.33, P<0.01\right)$. The presence of heterospecific competitors also increased the duration of the larval phase, and it was so for both experimental densities. At the lowest one, $B$. calamita metamorphosed a mean of $17.4 \mathrm{~d}$ later than in absence of B. bufo $\left(F_{1,19}=30.51, P<0.001\right)$ and also interacted significantly with water salinity, further increasing the larval period $\left(F_{1,19}=10.06, P<0.01\right)$. At high density the delay reached $20.3 \mathrm{~d}\left(F_{1,19}=10.49\right.$, $P<0.005)$. Mean mass at metamorphosis was clearly diminished when intraspecific density was increased $\left(F_{1,19}=9.11, P<0.01\right)$, from a mean mass of $91 \mathrm{mg}$ to $76 \mathrm{mg}$. The presence of $B$. bufo also reduced the body mass at metamorphosis, and the effect was significant at both densities. Interspecific competition at low densities caused a reduction of $\sim 16 \%$ of the body mass, while at high densities the reduction was $\sim 14 \%$. The effect of water salinity over the mean mass at metamorphosis was statistically significant $\left(F_{1,19}=\right.$ 14.64, $P<0.002$ ) and represented an increase in the mass of larvae under brackish conditions.

\section{DISCUSSION}

\section{Species level}

Water salinity caused a delayed metamorphosis in $B$. calamita (see Table 2). In turn, development of $B$. bufo was not significantly affected by osmotic stress. B. bufo is generally believed to be poorly resistant to water salinity, partly because it is usually absent from saline environments. Thus it is surprising to find that salinity as main effect did not affect either of the response variables of $B$. bufo in this study. The fact that $B$. bufo tadpoles were exposed to the brackish conditions at a later developmental stage than natterjacks may have reduced the negative effects of salinity. However, according to our data, the absence of $B$. bufo from brackish environments cannot be explained solely in terms of detrimental effects of salinity on the larvae. The impact of salinity on the embryos seems to be more acute in $B$. bufo when compared with higher tolerance in natterjack embryos (I. Gómez-Mestre and M. Tejedo, unpublished data) although other explanations such as breeding site selection may explain the pattern. On the other hand, the present experimental design may have low statistical power to detect the effect of water salinity by itself and we could only perceive it as a synergistic effect with other factors. The significant increase in mass at metamorphosis caused by water salinity in B. calamita is likely to be an indirect consequence of prolonging the larval period while food availability remains constant. Contrary to our predictions, the abiotic factor studied did not qualitatively alter the outcome of the competitive interaction, but merely intensified it, as has been the case in other systems studied (Pehek 1995).

Interspecific competition did occur between $B$. calamita and B. bufo in our experiment. The mutual effects were asymmetric, but led to a decrease in survival, a retardation of the larval period, and a reduced mean mass of the emerging toadlets for both species, reducing their fitness. Similar consequences of interspecific competition have also been reported for other competing anuran species (Wilbur 1982, Morin 1983a, $b$, Werner 1986, Warner et al. 1993, Baker and Beebee 1997, Bardsley and Beebee 1998a).

According to our predictions, B. bufo had a marked competitive effect (sensu Goldberg and Fleetwood 1987) over B. calamita (increased mortality, delayed metamorphosis, and decreased mass at metamorphosis), and also exhibited a stronger tolerance to competition than $B$. calamita. The competitive effect was asymmetric since survival of $B$. bufo was not significantly affected by $B$. calamita. $B$. bufo survival was only diminished when competition occurred at high density as an interaction with the increase in intraspecific competition. Differences in response to competition are also remarkable because $B$. calamita experienced an increase in the duration of the larval period more than twice the one experienced by $B$. bufo when they were set to compete (see Table 2 ). The relatively minor decrease in mass at metamorphosis showed by $B$. calamita with respect to $B$. bufo may be at least partially attributable to relaxed intraspecific density caused by mortality.

Competitive superiority among species is thought to be size dependent to a large extent (Connell 1983, Thompson 1988, Werner 1994). In the case of anuran larval guilds of phylogenetically close taxa, interspecific relative-size relationships are conditioned primarily by the time span between the breeding of the different species. Early breeders attain large sizes by the time other species lay their clutches and that difference may be translated into competitive superiority throughout the entire larval period (Alford and Wilbur 1985, Faragher and Jaeger 1998). In southern Spain $B$. bufo usually breeds earlier than $B$. calamita, when the autumn-winter rainfall is abundant enough, but it is also common that their breeding seasons greatly overlap when rainfall is more scarce or starts later. In our experiment, $B$. bufo tadpoles were two weeks older than B. calamita. Thus, B. calamita larvae could be expected a priori to be an inferior competitor in all interactions with $B$. bufo, a situation described for several UK populations (Bardsley and Beebee 1998 $a, b$ ). However, considering a resource basis of competition, if one species of a competing pair has a clear impact on the resource which is the object of the competition, it is conceivable to expect a certain degree of reciprocal effect, however slight it might be (Woodward 1982, Connell 1983, Alford and Wilbur 1985). Although the 
design employed in this study does not allow us to distinguish between resource and interference competition, it was observed that $B$. bufo also experienced negative effects resulting from the interaction with $B$. calamita. However, in the case of B. bufo, the detrimental effects of intraspecific competition exceeded those caused by interspecific competition, while the reverse was true for $B$. calamita (see Table 2), as was predicted. Superiority against heterospecific competitors suggests a strong competitive ability and has been shown to correlate with intense intraspecific competition (Wilbur 1982, Semlitsch and Walls 1993). Thus, if $B$. bufo is forced to spawn in more ephemeral ponds, the concomitant increase in intraspecific density may compromise its competitive superiority over B. calamita, a species customary to highly temporary ponds. Pond duration can alter the outcome of competition by reducing survival, even though the intensity of the interaction in terms of relative growth rate remains constant (Petranka and Sih 1986). As temporary ponds dry out, density increases, which may affect $B$. bufo more strongly than $B$. calamita, and ultimately modify the relative ratio of metamorphic success. A high density of conspecifics renders $B$. bufo more vulnerable to interspecific competition and to abiotic stress conditions. Similar phenomena have been demonstrated for other species, e.g., Bufo terrestris in relation to water temperature and dissolved oxygen (Travis and Trexler 1986), and the competing pair Hyla gratiosa-Hyla femoralis in relation to $\mathrm{pH}$ (Warner et al. 1991, 1993). Overall, interactions at different levels, synergism, and antagonism among biotic and abiotic factors (Newman 1998) may be the rule rather than the exception in generating diversification in ecological processes.

\section{Population level}

Our results confirmed the prediction that geographic variation exists among populations of $B$. calamita in their response to the biotic and abiotic factors under study, as a reflection of the local selective pressures. Water salinity had no effect on either Saline or Fresh 1 populations. B. calamita from the Saline population seem to have undergone processes of local adaptation to brackish water environments (I. Gómez-Mestre and M. Tejedo, unpublished data), and thus it was expected to be less sensitive to water salinity than those populations coming from freshwater environments. Lack of effect of osmotic stress on Fresh 1 could not be predicted in terms of its natural environmental conditions. Osmotic stress resistance could have evolved in Fresh 1 as selective response to particular environmental conditions, but given the relative geographic proximity of Fresh 1 and Saline, gene flow estimates would be required to exclude the possibility of inmigration of salinity-resistant genotypes. In contrast, Fresh 2 markedly delayed metamorphosis when reared under osmotic stress. Delaying metamorphosis in a brackish temporary pond forces tadpoles to face the risk of des- iccation of the pond and also the steady increase in salinity as water evaporates, greatly reducing survival probability.

Because different populations of the same species experience large variations in life history and morphological traits, interactions between species are not immutable (Thompson 1994, 1999, Fauth 1998), but they vary in both space and time as species coevolve and adapt to the regionally predominant environmental conditions. Interpopulational variation among amphibian species in competitive and predator-prey interactions is not uncommon (Fauth 1998). The three B. calamita populations examined here also differed in their response to competition with $B$. bufo. As indicated in Table 3, Fresh 1, naturally syntopic of $B$. bufo, experienced by far the least increase in larval period. Saline tadpoles showed a less acute retardation of larval period in the presence of heterospecifics than Fresh 2, which in addition decreased its mean mass at metamorphosis when B. bufo was present. Approaching the issue from another perspective, we can score the competitive effect of each of the three $B$. calamita populations on $B$. bufo. Only Fresh 1 and Saline reduced $B$. bufo survival, and only Fresh 1 gave this result under low density conditions (see Fig. 2). Furthermore, mean mass at metamorphosis of $B$. bufo was also more reduced by Fresh 1 than by the other two populations. Competitive effect and competitive response are not necessarily positively correlated (Goldberg and Landa 1991 ), but in the case of these B. calamita populations, the greater the effect on the heterospecific, the greater the resistance to interspecific competition.

Saline and Fresh 1 are naturally exposed to more extreme environments, suggesting that more resistant phenotypes have been selected in these populations. Saline breeds in a brackish pond with low predation and competitive intensities (B. bufo is virtually absent), but is exposed to a high degree of osmotic stress while Fresh 1 breeds in a mountain stream, with a shorter benign period for larval development and crowded with competitors, particularly B. bufo. Fresh 2, in turn, breeds in temporary freshwater ponds where $B$. bufo is absent. These differences among populations result from diverse local-differentiation processes under the specific environments where they have been evolving.

Our data support the notion that populations within any given species are not geographically homogeneous subsets sharing the same pattern and trait distribution (Thompson 1988). Rather, populations seem to vary in structure and dynamics, in their degree of specialization to the different environmental conditions found, both biotic and abiotic, and thus the type, intensity, and outcome of their interactions with other organisms are likely to be variable and environment specific. Most biotic interactions show a geographic mosaic dynamics at both the ecological (Tilman and Kareiva 1997, Bascompte and Solé 1998) and evolutionary time scales (Herrera 1988), resulting from the combination of phy- 
logenetic constraints, the biogeography of the interacting species, and stochastic and deterministic genetic phenomena acting on them (Thompson 1994, 1999, Gomulkiewicz et al. 2000). In that sense, we conclude that even though competitive superiority of $B$. bufo over $B$. calamita is generally true, the outcome of competition between these two species is to a great extent dependent on the particular surrounding abiotic conditions and is strongly mediated by density-dependent effects. Furthermore, the modulation of these interactions varies geographically among populations both because of the different environments experienced and because of the particular natural histories of the populations involved.

Future research should broaden the spectrum of populations screened to generalize the observed pattern in competitive ability and to estimate their underlying genetic variance within and among populations, while gaining insight on the proximate mechanisms mediating the competitive interaction.

\section{ACKNOWLEDGMENTS}

We want to thank Ricardo Reques for his assistance during the experiment. Claudia Keller, Jordi Bascompte, Pedro Jordano, and Ricardo Reques reviewed earlier drafts of this manuscript, providing useful comments that greatly improved the paper. This work was supported by grant PB96-0861 from Dirección General de Investigación Científica y Técnica (DGICYT) conceded to Miguel Tejedo and the predoctoral grant AP97 05421411 from the Dirección General de Enseñanza Superior e Investigación Científica to Iván Gómez-Mestre. Thanks also to the Consejería de Medio Ambiente de la Junta de Andalucia and the guarderia for providing the corresponding permits and facilities at the Reserva de la Laguna Amarga.

\section{Literature Cited}

Alford, R. A. 1999. Ecology: resource use, competition and predation. Pages 240-278 in R. W. McDiarmid and R. Altig, editors. Tadpoles: the biology of anuran larvae. Chicago University Press, Chicago, Illinois, USA.

Alford, R. A., and H. M. Wilbur. 1985. Priority effects in experimental pond communities: competition between Bufo and Rana. Ecology 66:1097-1105.

Baker, G., and T. J. C. Beebee. 1997. Microenvironmental effects on competition between Rana and Bufo larvae, and on the abundance of Prototheca richardsi, in small fishponds. Herpetological Journal 7:149-154.

Balinsky, J. B. 1981. Adaptation of nitrogen metabolism to hypertonic environment in Amphibia. Journal of Experimental Zoology 215:335-350.

Bardsley, L., and T. J. C. Beebee. 1998a. Interspecific competition between Bufo larvae under conditions of community transition. Ecology 79:1751-1759.

Bardsley, L., and T. J. C. Beebee. 1998b. Interspecific competition between larvae is not an important structuring force in mixed communities of Rana and Bufo on an English sand-dune system. Ecography 21:449-456.

Bascompte, J., and R. V. Solé, editors. 1998. Modelling spatiotemporal dynamics in ecology. Springer-Verlag, Berlin, Germany.

Beebee, T. J. C. 1985. Salt tolerances of natterjack toad (Bufo calamita) eggs and larvae from coastal and inland populations in Britain. Herpetological Journal 1:14-16.

Bernardo, J. 1994. Experimental analysis of allocation in two divergent, natural salamander populations. American Naturalist 143:14-28.

Berven, K. A. 1982a. The genetic basis of altitudinal variation in the wood frog Rana sylvatica. I. An experimental analysis of life history traits. Evolution 36:962-983.

Berven, K. A. 1982b. The genetic basis of altitudinal variation in the wood frog Rana sylvatica. II. An experimental analysis of larval development. Oecologia (Berlin) 52:360369.

Connell, J. H. 1983. On the prevalence and relative importance of interspecific competition: evidence from field experiments. American Naturalist 122:661-696.

Denton, J. S., and T. J. C. Beebee. 1994. The basis of niche separation during terrestrial life between two species of toad (Bufo bufo and Bufo calamita): competition or specialisation? Oecologia 97:390-398.

Dunson, W. A., and J. Travis. 1991. The role of abiotic factors in community organization. American Naturalist 138: 1067-1091.

Dunson, W. A., and J. Travis. 1994. Patterns in the evolution of physiological specialization in salt-marsh animals. Estuaries 17:102-110.

Faragher, S. G., and R. G. Jaeger. 1998. Tadpole bullies: examining mechanisms of competition in a community of larval anurans. Canadian Journal of Zoology 76:144-153.

Fauth, J. E. 1998. Investigating geographic variation in interspecific interactions using common garden experiments. Pages 294-415 in W. J. Resetarits and J. Bernardo, editors. Experimental ecology. Oxford University Press, Oxford, UK.

Figiel, C. R., and R. D. Semlitsch. 1990. Population variation in survival and metamorphosis of larval salamanders ( $\mathrm{Am}$ bystoma maculatum) in the presence and absence of fish predation. Copeia 5: 818-826.

Goldberg, D. E., and L. Fleetwood. 1987. Competitive effect and response in four annual plants. Journal of Ecology 75: 1131-1143.

Goldberg, D. E., and K. Landa. 1991. Competitive effect and response: hierarchies and correlated traits in the early stages of competition. Journal of Ecology 79:1013-1030.

Gomulkiewicz, R., J. N. Thompson, R. D. Holt, S. L. Nuismer, and E. Hochberg. 2000. Hot spots, cold spots, and the geographic mosaic theory of coevolution. American Naturalist 156:156-174.

Gosner, K. L. 1960. A simplified table for staging anuran embryos and larvae with notes on identification. Herpetologica 16:183-190.

Harris, R. N., R. D. Semlitsch, H. M. Wilbur, and J. E. Fauth. 1990. Local variation in the genetic basis of paedomorphosis in the salamander Ambystoma talpoideum. Evolution 44:1588-1603.

Herrera, C. M. 1988. Variation in mutualisms: the spatiotemporal mosaic of a pollinator assemblage. Biological Journal of the Linnean Society 35:95-125.

Hoffmann, A. A., and P. A. Parsons. 1991. Evolutionary genetics and environmental stress. Oxford University Press, Oxford, UK.

Hurlbert, S. H. 1984. Pseudoreplication and the design of ecological field experiments. Ecological Monographs 54: 187-211.

Kurzava, L. M., and P. J. Morin. 1994. Consequences and causes of geographic variation in the body size of a keystone predator, Notophtalmus viridescens. Oecologia 99: 271-280.

Merilä, J., A. Laurila, A. Timenes laugen, K. Rasanen, and M. Pahkala. 2000. Plasticity in age and size at metamorphosis in Rana temporaria: comparison of high and low latitude populations. Ecography 23:457-465.

Morin, P. J. 1983a. Predation, competition, and the compo- 
sition of larval anuran guilds. Ecological Monographs 53 $119-138$.

Morin, P. J. 1983b. Competitive and predatory interactions in natural and experimental populations of Notophthalmus viridescens dorsalis and Ambystoma tigrinum. Copeia 3: 628-639.

Newman, R. A. 1998. Ecological constraints on amphibian metamorphosis: interactions of temperature and larval density with responses to changing food level. Oecologia 115 : 9-16.

Parsons, P. A. 1996. Competition versus abiotic factors in variably stressful environments: evolutionary implications. Oikos 75:129-132.

Pehek, E. L. 1995. Competition, pH, and the ecology of larval Hyla andersonii. Ecology 76:1786-1793.

Petranka, J. W., and A. Sih. 1986. Environmental instability, competition, and density-dependent growth and survivorship of a stream-dwelling salamander. Ecology 67:729736.

Reques, R., and M. Tejedo. 1997. Reaction norms for metamorphic traits in natterjack toads to larval density and pond duration. Journal of Evolutionary Biology 10:829-851.

Rowe, C. L., and W. A. Dunson. 1995. Individual and interactive effects of salinity and initial fish density on a salt marsh assemblage. Marine Ecology Progress Series 128: 271-278

SAS Institute. 1990. SAS/STAT user's guide. Version 6 Fourth edition. SAS Institute, Cary, North Carolina, USA.

Schoener, T. W. 1983. Field experiments on interspecific competition. American Naturalist 122:240-285.

Searle, S. R. 1987. Linear models for unbalanced data. Wiley and Sons, New York, New York, USA.

Semlitsch, R. D., and S. C. Walls. 1993. Competition in two species of larval salamanders: a test of geographic variation in competitive ability. Copeia 3: 587-595.

Shoemaker, V. H., S. S. Hillman, S. D. Hillyard, D. C. Jackson, L. L. McClanahan, P. C. Withers, and M. L. Wygoda. 1992. Exchange of water, ions and respiratory gases in terrestrial amphibians. Pages 81-124 in M. E. Feder and W. W. Burggren, editors. Environmental physiology of the amphibians. Chicago University Press, Chicago, Illinois, USA.

Snedocor, G. W., and W. G. Cochran. 1989. Statistical methods. Iowa State University Press, Iowa City, Iowa, USA.

Sokal, R. R., and F. J. Rohlf. 1995. Biometry. W. H. Freeman, New York, New York, USA.

Storfer, A., and A. Sih. 1998. Gene flow and ineffective an- tipredator behavior in a stream-breeding salamander. Evolution 52:558-565.

Tejedo, M. 1992. Effects of body size and timing of reproduction on reproductive success in female natterjack toads (Bufo calamita). Journal of Zoology, London 228:545-555.

Tejedo, M., and R. Reques. 1994. Plasticity in metamorphic traits of natterjack tadpoles: the interative effects of density and pond duration. Oikos 71:295-304.

Thompson, J. N. 1988. Variation in interspecific interactions. Annual Review of Ecology and Systematics 19:65-87.

Thompson, J. N. 1994. The coevolutionary process. University of Chicago Press, Chicago, Illinois, USA.

Thompson, J. N. 1999. The raw material for coevolution. Oikos 84:5-16.

Tilman, D., and P. Kareiva. 1997. Spatial ecology: the role of space in population dynamics and interspecific interactions. Princeton University Press, Princeton, New Jersey, USA.

Travis, J. 1980. Phenotypic variation and the outcome of interspecific competition in hylid tadpoles. Evolution 34: 40-50.

Travis, J., and J. C. Trexler. 1986. Interactions among factors affecting growth, development and survival in experimental populations of Bufo terrestris (Anura: Bufonidae). Oecologia (Berlin) 69:110-116.

Underwood, T. 1986. The analysis of competition by field experiments. Pages 240-268 in J. Kikkawa and D. J. Anderson, editors. Community ecology: pattern and process. Blackwell Scientific, Melbourne, Victoria, Australia.

Warner, S. C., W. A. Dunson, and J. Travis. 1991. Interaction of $\mathrm{pH}$, density, and priority effects on the survivorship and growth of two species of hylid tadpoles. Oecologia (Berlin) 88:331-339.

Warner, S. C., J. Travis, and W. A. Dunson. 1993. Effect of $\mathrm{pH}$ variation on interspecific competition between two species of hylid tadpoles. Ecology 74:183-194.

Werner, E. E. 1986. Amphibian metamorphosis: growth rate, predation risk, and the optimal size at transformation. American Naturalist 128:319-341.

Werner, E. E. 1994. Ontogenetic scaling of competitive relations: size-dependent effects and responses in two anuran larvae. Ecology 75:197-213.

Wilbur, H. M. 1982. Competition between tadpoles of Hyla femoralis and Hyla gratiosa in laboratory experiments. Ecology 63:278-282.

Wilbur, H. M., and J. P. Collins. 1973. Ecological aspects of amphibian metamorphosis. Science 182:1305-1314.

Woodward, B. D. 1982. Tadpole competition in a desert anuran community. Oecologia 54:96-100. 